\title{
La expedición de Balmis
}

\author{
ENRIQUE LAVAL R.
}

\section{The Balmis expedition}

La llamada Real Expedición Filantrópica de la Vacuna fue confiada por Carlos IV al médico valenciano don Francisco de Balmis y Berenguer, con el propósito de propagar la vacuna antivariólica en América y Filipinas.

La expedición partió de La Coruña el 30 de noviembre de 1803 en la corbeta "María de Pita" y arribó a Puerto Cabello, en Venezuela, el 19 de marzo de 1804. En el trayecto vacunó en Tenerife y Puerto Rico, de acuerdo con lo establecido en la circular enviada por el ministro don José Antonio Caballero.

La circular recibida en Chile y dirigida en términos análogos a todas las autoridades de Indias, concluye así:

Finalmente espera el Rey del celo acreditado de V.E. a su Real Servicio que con la persuasión y demás medios que juzgue afortunados, contribuyan a introducir y conservar en todos los pueblos de su mando y de las islas de Chiloé la saludable práctica de la vacuna, haciéndoles notoria la expedición para que la proteja, y a sus individuos con todos los auxilios que dictan la humanidad y la importancia del objeto, y para que envíen a esa Capital Facultativos que aprendan la práctica de la operación y que lleven el fluido; en la inteligencia de que la obligación del Director y de sus subalternos se limita a las capitales, a los pueblos de tránsito y algún otro punto que se estime preciso y debiendo pasar aquéllos de ese Reino a Buenos Aires para regresar a España.

San Ildefonso, $1^{\circ}$ de octubre de 1803. José Antonio Caballero.

\section{Al Presidente y Capitán General de Chile.}

A bordo de la corbeta iba Balmis con diez facultativos abnegados y con veinticinco niños, acompañados por sus madres o nodrizas, los que debían conservar el fluido vaccinal brazo a brazo, durante la prolongada travesía. Estos niños, por acuerdo del monarca, fueron adoptados como hijos especiales de la nación española.

La expedición se dividió en Venezuela en dos: una a cargo del propio Balmis, para vacunar en México y Filipinas, y otra dirigida por el médico catalán José Salvany y Lleopart e integrada por los doctores Grajales. Lozano y Bolaños, destinada a vacunar en América del Sur.

El doctor Manuel Julián Grajales por orden de Salvany pasó desde el Perú a Chile, a seguir la tarea contraída ante el Gobierno de España.
En el siguiente documento Grajales da cuenta al Gobierno de Chile, de su venida a este país:

\section{Exmo. Señor:}

Participo a V.E. mi destino a este Reyno a propagar el fluido vacuno que a mi cargo se ha confiado; pero estando esta superioridad con la incertidumbre si o no existe la Vacuna en ese Reyno, pues de notoriedad se sabía que se había en él propagado, ha determinado de anunciar a V.E. lo que ha tenido por más conveniente: mas sin embargo, he de merecer de la atención de V.E. me comunique si o no se propaga todavía el dicho fluido, para no trasmitirlo por mar de brazo a brazo y no imponer mayores gastos al Real Herario. Igualmente estimare que V.E. dé órdenes a los Puertos de su mando, por si arribare a algunos de ellos, me den auxilios que las Reales Ordenes previenen.

Al Exmo. Sor. Don Luis Muñoz de Guzmán. Tente. Gral. de los Rs. Excerts., Presidente y Capn. Gral. del Reyno de Chile. Lima y marzo 7 de 1807.

No estaba equivocado Grajales sobre la existencia de la vacuna en Chile, como veremos a continuación.

El 5 de julio de 1805 ancló en Montevideo la fragata portuguesa "Rosa del Río", al mando del capitán don Manuel José Días. Su propietario, don Antonio Machado Carballo, portugués, conducía un cargamento de 38 negros esclavos, y para preservar su repugnante negocio, los había vacunado de brazo a brazo y, además, traía vacuna conservada en vidrios. El gobernador de Montevideo, don Pascual Ruiz Huidobro, deseó observar si se trataba de la verdadera vacuna, internando en el Hospital Provisional a los últimos tres negros vacunados. Los informes fueron desalentadores: uno de los tres negros contrajo la viruela y en los otros dos la vacuna no prendió, pero por su parte el cirujano don Cristóbal Martín Montufar, con la vacuna conservada en vidrios, que le había sido proporcionada por don Antonio Machado Carballo, vacunó cuatro niños y tuvo pleno éxito.

Enterado el virrey Marqués de Sobremonte, de la introducción de la vacuna en Montevideo, el 16 de julio le escribía a Ruiz Huidobro ordenándole el envío de la vacuna a Buenos Aires. Sin embargo, parece que el mismo Machado la remitió directamente a aquella ciudad, y luego se trasladó él con dos negros recién vacunados. De inmediato el Marqués de Sobremonte la envió a las provincias de Salta y Córdoba y a los indios guaraníes, a Chile y Lima 
por medio de vidrios y en polvos $y$, aunque no había prendido en Charcas repitió la remesa.

En Chile se recibió la vacuna a fines de septiembre o comienzos de octubre, y se aplicó por primera vez el 8 de octubre de 1805 en el pórtico de la Catedral de Santiago, por el fraile juandediano padre Pedro Manuel Chaparro.

El presidente de Chile, don Luis Muñoz de Guzmán, en oficio de 10 de noviembre de 1805 , acusó recibo de la vacuna al Marqués de Sobremonte, le comunicó que había encargado su aplicación al padre Chaparro y le incluyó un informe de éste en que expresa haber vacunado hasta la fecha 286 personas, en quienes prendió felizmente el fluido a excepción de las 14 primeras, gracias a el presidente y su esposa que influyeron mucho con su persuasión y ejemplo a la buena acogida.

En los últimos días del año 1807, llegó a Valparaíso el doctor Manuel Julián Grajales, iniciando de inmediato sus trabajos. El 21 de enero de 1808 ya había organizado la Junta de Vacuna en Valparaíso, con el siguiente personal: el alcalde de primer voto, el cura párroco, el procurador de ciudad, dos vecinos y el médico don José Olea.

De los médicos españoles que pasaron por Chile en la primera mitad del siglo XIX, quizás ninguno dejó un recuerdo más grato y perdurable que Grajales; pocos gozaron como él de tan singular prestigio por su saber y quehacer médico, al cual rodeó del más profundo respeto, y por sus condiciones personales impregnadas de gran generosidad.

\section{Bibliografía}

1.- Laval M E. La viruela en Chile. An Chil Hist Med 1967-1968; 9-10: 203.

2.- Ferrer P L. Historia General de la Medicina en Chile. Tomo 1. Impta. Talca. Talca, Chile, 1904.

3.- Vicuña Mackenna B. Los Médicos de Antaño en el Reino de Chile. Santiago de Chile. Ed. Rafael Jover, 1877.

4.- Salas Olano E. Historia de la Medicina en Chile. Santiago de Chile, Impta. Vicuña Mackenna, 1894.

5.- Castiglioni A. Historia de la Medicina. Barcelona, España. Ed. Salvat, 1941. 